\title{
High temperature bi-axial low cycle fatigue behaviour of railway wheel steel
}

\author{
Dimitrios Nikas ${ }^{1, *}$ and Johan Ahlström ${ }^{1, * *}$ \\ ${ }^{1}$ Division of Engineering Materials, Department of Industrial and Materials Science, Chalmers University \\ of Technology, 41296 Gothenburg, Sweden
}

\begin{abstract}
One of the most important aspects in railway operation is the interaction between rail and wheel. Railway wheels are commonly made from medium carbon steels $(\sim 0.55 \mathrm{wt} . \% \mathrm{C})$, heat treated to a near pearlitic microstructure with some $5-10 \%$ pro-eutectoid ferrite. During the operation of freight trains, where block brakes are used, high thermal loads are evolved because of recurring braking and occasional slippage. Thus the combination of mechanical and thermal loads leads to changes in the mechanical properties of the material. The focus of the current investigation is to evaluate the mechanical behaviour of wheel material (UIC ER7T) subjected to non-proportional biaxial fatigue loading, as this simulates the actual working conditions in a better way than uniaxial loading. Axial-torsional low cycle fatigue tests were performed at room temperature and elevated temperatures using thin walled specimens to study the cyclic stress-strain properties of this material. The results showed large influence of temperature on the ratcheting behaviour of the material. Biaxial non-proportional loading gave much higher strain hardening as compared to uniaxial loading. Hardening due to dynamic strain ageing can be seen in the biaxial tests at temperatures around $300^{\circ} \mathrm{C}$.
\end{abstract}

\section{Introduction}

One of the common engineering applications for steel these days lies within the railway industry, for the manufacturing of rails and wheels. These steels have a predominantly pearlitic microstructure and specifically for wheel material, they consist of carbon steels with around 0.55 wt.\% carbon. The forging and subsequent heat treatment that these wheels undergo, produces a fine pearlitic microstructure with some $5 \%$ proeutectoid ferrite. Steels with this microstructure exhibit a very good combination of wear and strength properties, which are very suitable for railway applications. In this study, the wheel material ER7T [1] is studied, which is the dominant material for use on freight trains in Europe [2]. With running speeds and axle loads of trains increasing in the recent years, these wheel materials are subjected to ever increasing demands on their performance. Especially for freight trains, where block braking is used, high thermal loads are evolved. Temperatures can reach over $500^{\circ} \mathrm{C}$ in the wheel tread during freight operation [3] which can be problematic for the material's microstructural integrity. Pearlite is a lamellar microstructure consisting of colonies of similarly oriented

\footnotetext{
*e-mail: nikas@chalmers.se

**e-mail: johan.ahlstrom@chalmers.se
} 
cementite lamellas embedded in a softer ferrite matrix. When exposed to high temperatures for prolonged periods of time, spheroidisation of the microstructure can take place, which severely softens the material $[4,5]$. Moreover the contact forces developed in the contact area are also the direct cause of the damage of wheels and rails like wear, corrugation, rolling contact fatigue and fracture. After the material has experienced plastic deformation, it becomes even more prone to spheroidisation of the lamellas during exposure to high temperatures [4]. It is thus relevant to understand the high temperature performance of wheel material and to evaluate the change in fatigue behaviour after thermal exposure. Because of the rolling contact loading, multiaxial stress states develop. Biaxial experiments with non-proportional loading at elevated temperature simulates the actual working conditions in a better way than uniaxial loading.

Previous work by the authors [4, 6] and others [5] on virgin material ER7T showed that uniaxial low cycle fatigue loading at an elevated temperature leads to a cyclic hardening at temperatures around $300^{\circ} \mathrm{C}$ due to dynamic strain ageing (DSA), and cyclic softening at higher temperatures due to combined microstructure degeneration by spheroidisation and increasing dislocation mobility with increasing temperature. One group of researchers [7] evaluated the room temperature (RT) multiaxial fatigue strength of ER7T wheel steel under combined out-of-phase alternating torsion and pulsating compressive axial loads, which is similar to that observed under the contact area of the wheel. High strength rail steels were examined by Pun et al [8] regarding the cyclic plastic response to different bi-axial compression-torsion loading paths. These experiments were done only at room temperature, but included both non-proportional loading and ratcheting.

The wheels on block-braked trains often experience combined thermal and mechanical loadings, with non-proportional stresses at elevated temperature. To this end the focus of this paper is to characterise the behaviour of ER7T wheel material using such conditions. Out of phase axial-torsional low cycle fatigue tests were performed at room temperature and at elevated temperatures to study the bi-axial fatigue properties. The non-proportional strain hardening was quantified and the effect on fatigue life was estimated. The results were compared with previous uniaxial low cycle fatigue experiments on the same material $[4,6]$.

\section{Material and experimental}

The material studied in this investigation is the railway wheel steel ER7T. This material follows the standard EN 13262-1 [1] with a near-pearlitic microstructure and a chemical composition as shown in table 1.

Table 1. Chemical composition of R7T wheel material, in wt $\%$

\begin{tabular}{ccccccccccc}
\hline $\mathrm{C}$ & $\mathrm{Si}$ & $\mathrm{Mn}$ & $\mathrm{Mo}$ & $\mathrm{S}$ & $\mathrm{Cr}$ & $\mathrm{Cu}$ & $\mathrm{Ni}$ & $\mathrm{V}$ & $\mathrm{P}$ & $\mathrm{Fe}$ \\
\hline 0.50 & 0.36 & 0.80 & 0.03 & 0.002 & 0.2 & 0.15 & 0.12 & 0.023 & 0.008 & Bal. \\
\hline
\end{tabular}

The manufacturing process of this wheel material consists of forging, heat treatment, rim chilling and annealing. Within the standard, the material designation is ER7, but here the commonly used name R7T will be used. The "T" added to the designation marks that the wheels have been rim chilled; during production the tread and flange are cooled with water jets after austenitization. This creates a fine-pearlitic microstructure close to the rim with a slight decrease in hardness and strength and a slight increase in free ferrite and interlamellar spacing with increasing depth. 


\subsection{Test bar extraction and preparation}

Because of the rim chilling process tensile and fatigue properties of specimens vary slightly with radial distance from the wheel running surface. For this investigation square section bars were extracted from a virgin R7T wheel $20 \mathrm{~mm}$ below the running surface as shown in figure 1 .

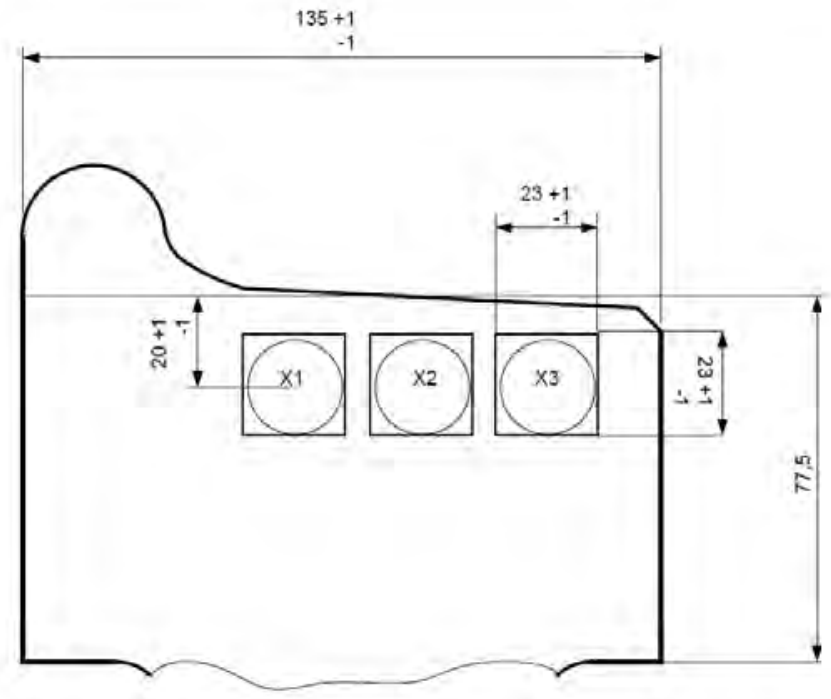

Figure 1. Wheel rim cross section. The sketch describes how samples were extracted from the wheel for the thin-walled specimens (in $\mathrm{mm}$ ). All bars were taken approximately $20 \mathrm{~mm}$ below the running surface.

These bars were then turned between centers into cylindrical bars and thereafter drilled to create thin-walled fatigue test bars with their final geometry shown in figure 2. Care was taken during the machining process to achieve a very smooth inner and outer surface so that minimal grinding and polishing would be needed after. The bars were then ground and polished on their outer surface in a few steps using 1200 to 4000-grit paper, and a mirror-like finish was obtained on the outside surface.

\subsection{Multiaxial fatigue tests}

Biaxial axial torsion fatigue tests were carried out on the aforementioned thin walled test bars. The experiments consisted of alternating tension/compression and torsion applied in so called out-of-phase loading with a $90^{\circ}$ phase lag which is assumed to give the maximum amount of strain hardening [9]. The tests were conducted at a constant total equivalent Von Mises strain amplitude loading at $\Delta \varepsilon_{t} / 2=0.6 \%$ and $\Delta \varepsilon_{t} / 2=1.0 \%$ until failure. Such loading mode gives a circular strain path. The tests were conducted on an MTS 809 servo-hydraulic biaxial rig capable of applying axial load up to $100 \mathrm{kN}$ and max torque of $1100 \mathrm{Nm}$. The machine was equipped with an induction coil that was used to perform isothermal tests at high temperatures. Three elevated temperatures were selected for the experiments, namely $200^{\circ} \mathrm{C}, 300^{\circ} \mathrm{C}$ and 400 ${ }^{\circ} \mathrm{C}$ to complement the tests at room temperature. A high temperature extensometer was used for all tests, with gauge length as low as $12 \mathrm{~mm}$, to avoid large temperature gradients in the 


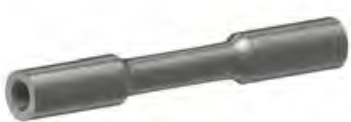

(a)

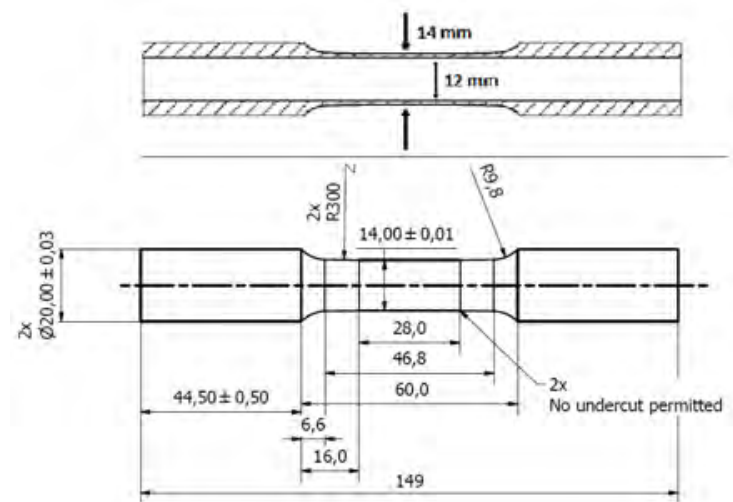

(b)

Figure 2. Geometry of thin-walled test bars for biaxial tests (in $\mathrm{mm}$ )

tested material volume. The setup can be seen in figure 3. A sinusoidal waveform was used at a frequency of $0.25 \mathrm{~Hz}$ for the $1.0 \%$ tests and $0.4 \mathrm{~Hz}$ for the $0.6 \%$ tests. Experiments at room temperature were run at a lower frequency of $0.1 \mathrm{~Hz}$, since a significant temperature increase has been observed in thin walled specimens at higher plastic strain rates. This effect is negligible at the elevated temperatures, where the temperature is regulated via feedback to the power controller for the induction coil. All test parameters are shown in table 2 below.

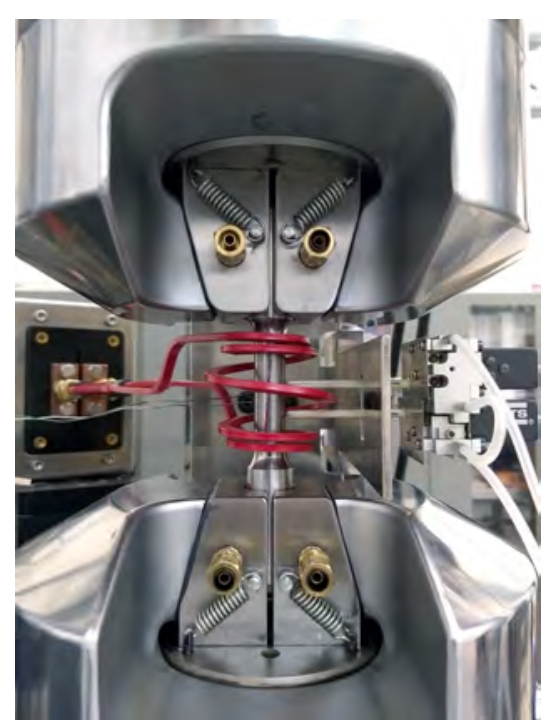

Figure 3. Experimental setup for high temperature biaxial testing 
Table 2. Loading path and parameters

\begin{tabular}{llll}
\hline Temperature & Loading path & Strain path & $\begin{array}{l}\text { Equivalent } \\
\text { strain, } \epsilon_{e q}(\%)\end{array}$ \\
\hline $\begin{array}{l}\mathrm{RT}, \quad 200^{\circ} \mathrm{C}, \\
300^{\circ} \mathrm{C}, 400^{\circ} \mathrm{C}\end{array}$ & $\begin{array}{l}\text { non-proportional } \\
\text { loading }\left(90^{\circ}\right)\end{array}$
\end{tabular}

\section{Results}

The equivalent von Mises peak stress development is shown in figure 4. All conditions exhibit a very rapid initial hardening within the first one or two cycles of the test. After that, a differentiation in behaviour occurs depending on the temperature. At room temperature, there is little further hardening after the initial cycles. At $300^{\circ} \mathrm{C}$, a continuous hardening can be seen throughout the fatigue life, however with a decreasing rate. At $0.6 \%$ the slope in the $\log (\mathrm{N})$ plot is constant until failure, whereas at $1.0 \%$ there is a saturation and then decrease in peak stress before failure. At $200^{\circ} \mathrm{C}$, the behaviour is similar, but with a lower rate of hardening and lower stress levels. At $400^{\circ} \mathrm{C}$, a slight variation in peak stress levels between each cycle is observed, with some little hardening during most of the fatigue life and softening towards the end. The cycle to cycle variation visible at the higher temperatures is thought to partly result from the temperature control, since no thermal strain compensation was applied. The total strain control thus imposed a slightly varying mechanical strain amplitude as a result of minor variation in test bar temperature due to pulsed power to the inductor. It has also been observed in previous experiments resulting in DSA. The effect on the results is judged to be small. Generally, the fatigue life is much shorter for the tests run at $1.0 \%$ strain amplitude.

From previous experiments with uniaxial straining, dynamic strain ageing was found to be the explanation for the increased cyclic hardening at temperatures around $300^{\circ} \mathrm{C}[3,4,6]$. The mechanism seems even stronger for out-of-phase (OP) loading. At $400^{\circ} \mathrm{C}$, there is a balance between the increased flow stress from dynamic strain ageing and a limiting flow stress from viscoplastic behaviour at elevated temperatures. The result is a rather constant peak stress throughout the test, which was also observed in previous uniaxial tests. As compared to the uniaxial tests, fatigue lives are drastically reduced for equivalent strain amplitudes.

Similar observations can be made in figures 5 and 6, where the development of the peak axial and torsional stress components are plotted separately. Torsional stress levels are always plotted as $\sqrt{3} \tau$. The axial peak stresses in the third cycle as compared to uniaxial straining is almost $20 \%$ higher in OP loading [4, 6]. The test run at $300^{\circ} \mathrm{C}$ at $1 \%$ strain amplitude shows signs of strain localisation, since the axial peak stress drops while the torsional decreases less.

\section{Discussion}

An attempt is made to quantify the out of phase (non-proportional) hardening, by comparing to the results in $[4,6]$. To do this we plot, for a given strain amplitude $(0.6 \%$ and $1 \%)$, the stress amplitude of a stabilised loop for each test, usually taken at the half life hysteresis loop. For the biaxial tests, this stress amplitude is calculated using the average von Mises equivalent stress for that loop: 


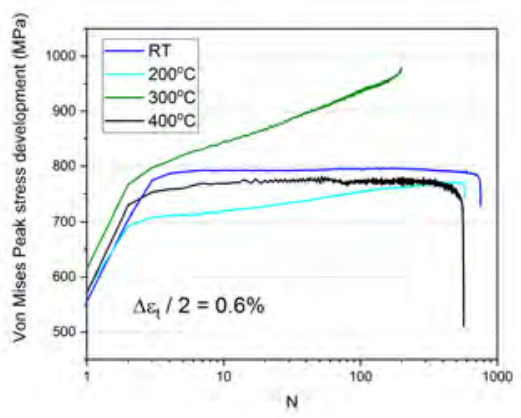

(a)

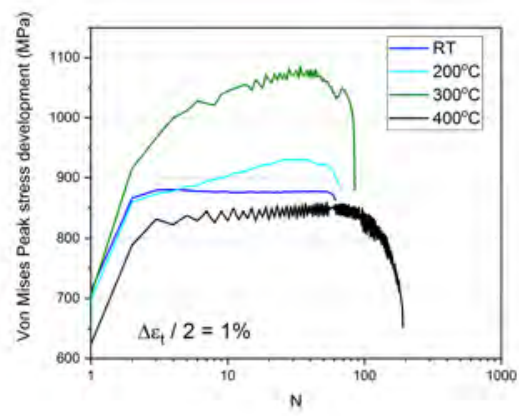

(b)

Figure 4. von Mises peak stress development for the various temperatures tested versus the cycle number. Strain amplitude of (a) $0.6 \%$, and (b) $1.0 \%$

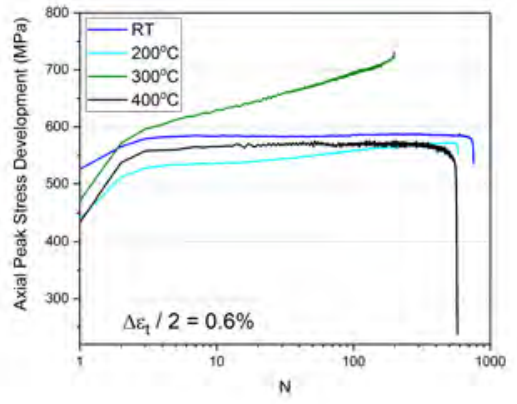

(a)

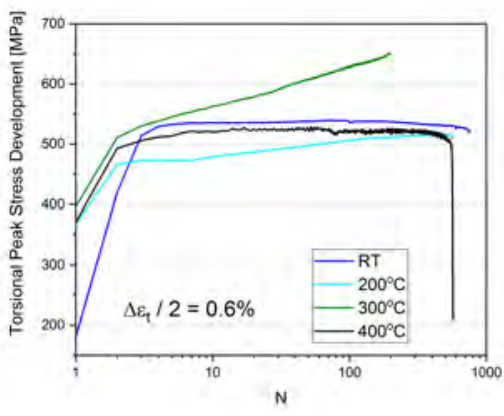

(b)

Figure 5. Axial and torsional peak stress development for the various temperatures tested versus the cycle number. Strain amplitude of $0.6 \%$

$$
\sigma_{e q}=\sqrt{\sigma^{2}+3 \tau^{2}}
$$

In figure 7, the comparison between uniaxial and biaxial experiments is shown with the most relevant area of the graph magnified for clarity. The points connected with lines are the recently performed biaxial experiments and the points without lines are the previously done uniaxial tests.

The main effect of non-proportional biaxial loading when compared to the uniaxial tests is the increase of strain hardening in the material for all temperatures. The difference reaches its peak around the $300^{\circ} \mathrm{C}$ temperature, probably assisted by a hardening contribution from DSA, both in uniaxial and biaxial loading and is observed in both $1.0 \%$ and $0.6 \%$ strain amplitude tests, but with a difference in stress levels.

In table 3, this effect is quantified for the two temperatures, where the effect is the largest when we go from uniaxial to biaxial loading.

The largest relative hardening effect is observed at $200^{\circ} \mathrm{C}$ and $1.0 \%$ strain amplitude with the increase reaching around $28 \%$. The other conditions also show an increase in 


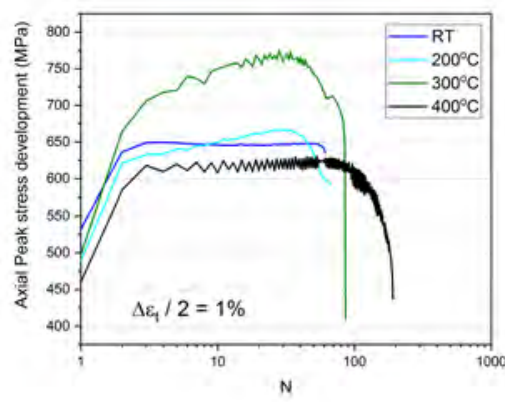

(a)

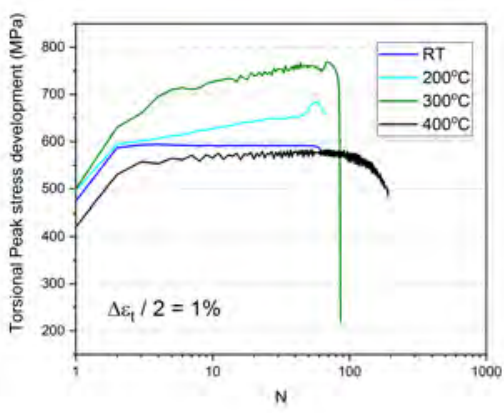

(b)

Figure 6. Axial and torsional peak stress development for the various temperatures tested versus the cycle number. Strain amplitude of $1.0 \%$

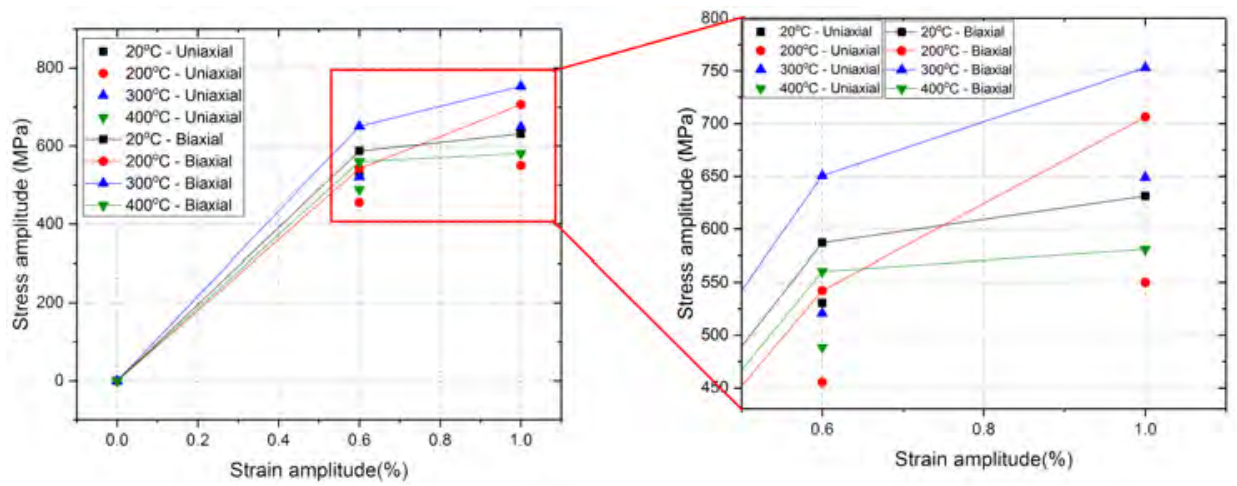

Figure 7. Stabilised loop stress amplitude vs strain amplitude for a set of uniaxial and biaxial data. Area of interest is magnified on the right

Table 3. Strain hardening increase

\begin{tabular}{lcc}
\hline & \multicolumn{2}{c}{ Equivalent strain, $\epsilon_{e q}(\%)$} \\
& $\mathbf{0 . 6 \%}$ & $\mathbf{1 . 0 \%}$ \\
\hline $200^{\circ} \mathrm{C}$ & $19 \%$ & $28 \%$ \\
$300^{\circ} \mathrm{C}$ & $25 \%$ & $16 \%$ \\
\hline
\end{tabular}

strain hardening with the total average of around $22 \%$. An interesting observation is that the highest hardening at $0.6 \%$ is happening at $300^{\circ} \mathrm{C}$ while the highest at $1.0 \%$ is happening at $200^{\circ} \mathrm{C}$. The explanation is difficult to tell from this study, since the interaction between strain hardening and DSA varies between the different cases. The strain localisation occurring, could also be part of the explanation as to why the test at $1.0 \% 200^{\circ} \mathrm{C}$ shows a comparatively small hardening. 


\section{Conclusion}

In the present study, the fatigue behaviour of wheel material was investigated using nonproportional biaxial low cycle fatigue testing. The main goal of the investigation in this paper was to compare the biaxial loading behaviour of this material with uniaxial fatigue tests performed in a previous work by the authors. It was found that:

- Biaxial loading gives much higher strain hardening as compared to uniaxial loading with the maximum value reaching almost $28 \%$ and an average of $22 \%$ in the testing conditions examined in this study.

- All biaxial tests exhibit the same initial hardening within the first one or two cycles, but then their behaviour differentiates depending on temperature. At room temperature no further hardening is observed, while at $300^{\circ} \mathrm{C}$ continuous hardening until the end of the test occurs, attributed to dynamic strain ageing. This was also observed in the uniaxial ratcheting tests and the previously performed strain controlled fatigue tests, but the mechanism seems even stronger for non-proportional biaxial loading.

- Fatigue life of the material is greatly decreased when the material is subjected to biaxial non proportional loading, with $1.0 \%$ strain amplitude tests exhibiting the shortest fatigue life.

\section{Acknowledgments}

This work has been a part of research activities within the Centre of Excellence CHARMEC (CHAlmers Railway MEChanics, www.charmec.chalmers.se). It is partly financed within the European Horizon 2020 Joint Technology Initiative Shift2Rail through contract No. 730841. The authors would also like to thank Knut Andreas Meyer for the design and manufacturing of the hollow test bars and his kind contribution to the drawing in figure 2.

\section{References}

[1] European standard for Wheels EN 13262- Product requirements, Tech. rep. (2009)

[2] K. Mädler, M. Bannasch, Materials used for Wheels on Rolling Stock, 7th World Congress on Railway Research (2006)

[3] F. Walther, D. Eifler, Fatigue behaviour of railway wheels at different temperatures, Materials Testing 46, 158 (2004)

[4] D. Nikas, J. Ahlström, A. Malakizadi, Mechanical properties and fatigue behaviour of railway wheel steels as influenced by mechanical and thermal loadings, Wear 366-367, 407 (2016)

[5] C.J. Peters, D. Eifler, Influence of Service Temperatures on the Fatigue Behaviour of Railway Wheel and Tyre Steels, Materials Testing 51, 748 (2009)

[6] J. Ahlström, LCF Loop shape in near pearlitic steels - Influence of temperature, in Proceedings of 7th International Conference on Low Cycle Fatigue, Aachen (2013)

[7] A. Bernasconi, M. Filippini, S. Foletti, D. Vaudo, Multiaxial fatigue of a railway wheel steel under non-proportional loading, International Journal of Fatigue 28, 663 (2006)

[8] C.L. Pun, Q. Kan, P.J. Mutton, G. Kang, W. Yan, Ratcheting behaviour of high strength rail steels under bi-axial compression-torsion loadings: Experiment and simulation, International Journal of Fatigue 66, 138 (2014)

[9] A. Fatemi, N. Shamsaei, Multiaxial fatigue: An overview and some approximation models for life estimation, International Journal of Fatigue 33, 948 (2011) 